\title{
Comparison of Extractive Components between Raw and Salted Alaska Pollack Roe ("Tarako")
}

\author{
Tze-Kuei Chiou, ${ }^{* 1,2}$ Takashi Matsui, and Shoji Konosu*1 \\ (Received August 13, 1988)
}

\begin{abstract}
Alaska pollack roe and its salted product ("Tarako") were analyzed extensively for nitrogenous and nonnitrogenous extractive components to elucidate their changes during salting. The change in proximate composition was also examined. The results obtained are summarized as follows.

1) The protein content decreased somewhat, but the lipid content hardly changed during the salting. The content of ash increased remarkably due to salting, and the extractive nitrogen increased to some extent.

2) As for the nitrogenous extractive components in the roe, free amino acids, especially Tau, Ala, Glu, and Leu, were predominant. Considerable amounts of creatine, trigonelline, and trimethylamine oxide were also found. The levels of nucleotides and related compounds were rather low.

3) Among the analyzed nonnitrogenous extractive components in the roe, lactic acid and inorganic ions, such as $\mathrm{Na}^{+}, \mathrm{K}^{+}, \mathrm{Cl}^{-}$, and $\mathrm{PO}_{4}{ }^{3-}$, were dominant. It is noticeable that a relatively large amount of sugar alcohols was detected.

4) The most striking changes in extractive components during the salting were the large decrease in Tau and the large increase in $\mathrm{Na}^{+}$and $\mathrm{Cl}^{-}$.

5) Free amino acids and inorganic ions were found to constitute the most part of extractives from "Tarako", suggesting that they were the principal contributors to its flavor.
\end{abstract}

Succeeding the previous study, in which the changes in extractive components of mullet roe during the processing into salted and dried product (Japanese name, "Karasumi") were investigated, ${ }^{\text {) }}$ a similar study was conducted on Alaska pollack roe.

The Alaska pollack is one of the most economically important fish in Japan. Its catch amounted to about 1.4 million tons in recent years. ${ }^{2)}$ The flesh of the fish is mostly processed into "Surimi" which is used for the production of "Kamaboko" and related products. Its ovary, a by-product, is chiefly processed into salted product called "Tarako" in Japan. The production of "Tarako" showed a steady increase in recent five years and reached a level as high as $57,000 t$ in $1986,{ }^{22}$ since it is one of the most popular seafoods and in strong demand in our country. For these reasons, our studies on the extractive and flavor components in seafoods aimed at those in the roe and "Tarako" to examine their changes during the salting.

\section{Materials and Methods}

\section{Roe Samples}

Alaska pollacks Theragra chalcogramma caught in the northern Pacific Ocean in September, 1984 were used. The average body length, body weight, and gonado-somatic index were $44 \mathrm{~cm}, 650 \mathrm{~g}$, and 2.6, respectively. After being removed and washed with sea water, the roes (raw material) were soaked in about $15 \%$ salt (sodium chloride) solution for $40-60 \mathrm{~min}$ and drained for about $1 \mathrm{~h}$ ("Tarako"). The raw material and "Tarako" from 20 fish each were frozen and stored at $-30^{\circ} \mathrm{C}$ until analyses.

Prior to the proximate analysis and the preparation of extracts, the roe samples were thawed at $4^{\circ} \mathrm{C}$ overnight, the ovary membranes were discarded, and the eggs were mixed well in a mortar.

\section{Methods}

The methods used in this study for the proxi-

*1. Laboratory of Marine Biochemistry, Faculty of Agriculture, The University of Tokyo, Bunkyo, Tokyo 113, Japan (邱 思魁, 松居 隆, 激巣章二: 東京大学篦学部水産化学研究室).

*2 Present address: Department of Marine Food Science, National Taiwan College of Marine Science and Technology, Keelung 200, Taiwan, Republic of China (国立台浮海洋学院水産食品科学系). 
mate analysis, the preparation of extracts, and the determinations of various extractive components in both samples were the same as those described previously. ${ }^{12}$

\section{Results}

\section{Proximate Composition and Extractive Nitrogen}

The proximate compositions of the raw material and "Tarako" are presented in Table 1. The moisture of raw material was $71.8 \%$, while that of "Tarako" was $64.7 \%$. The protein decreased slightly and the lipid hardly changed during the salting. The ash increased greatly from $8.2 \%$ in the raw material to $19.6 \%$ in "Tarako" due to the salting.

The extractive nitrogen (EN) which amounted to $606 \mathrm{mg}$ (Unless otherwise stated, the amounts of $\mathrm{EN}$ and extractive components are expressed in terms of $\mathrm{mg}$ in $100 \mathrm{~g}$ dry matter.) in the raw material increased to $652 \mathrm{mg}$ in "Tarako". The content of EN in the raw material is higher than that in the mullet roe, ${ }^{1)}$ but still lower than those reported for eggs of sea water fish such as saury, flying fish, and flathead flounder. ${ }^{\text {s) }}$

Table 1. Proximate composition and extractive nitrogen (EN) of raw and salted Alaska pollack roe ("Tarako")

\begin{tabular}{lccrrr}
\hline & \multirow{2}{*}{ Moisture } & \multicolumn{4}{c}{ On dry basis } \\
\cline { 3 - 6 } & & Protein & Lipid & Ash & EN \\
\hline Raw material & 71.8 & 78.7 & 6.7 & 8.2 & 0.606 \\
"Tarako" & 64.7 & 70.3 & 6.0 & 19.6 & 0.652 \\
\hline
\end{tabular}

\section{Free and Combined Amino Acids}

The contents of free (FAA) and combined amino acids (CAA) are shown in Table 2. Among FAA in the raw material, Tau $(1,103 \mathrm{mg})$ was prominent, amounting to $35 \%$ of the total FAA, but it decreased remarkably during the salting. On the contrary, most of the major FAA in the raw material such as Thr, Ser, Gln, Val, Leu, and Arg increased more or less during the salting. Consequently, the total amount of FAA hardly changed, but that of FAA excluding Tau gained an increase of $14 \%$.

The levels of CAA in the raw material were rather low as compared with those of FAA except ethanolamine which exceeded $140 \mathrm{mg}$. Its origin is unknown at present and worth to study. At least, a part of combined glycine might be derived from nucleotides and related compounds.") Most
Table 2. Free and combined amino acids of raw and salted Alaska pollack roe ("Tarako")

(mg/100 g dry matter)

\begin{tabular}{lcc}
\hline & Raw material & "Tarako" \\
\hline Taurine & 1,103 & 770 \\
Aspartic acid & $81(20)^{*}$ & $94(57)$ \\
Threonine & $103(26)$ & $123(38)$ \\
Serine & $107(42)$ & $132(57)$ \\
Glutamic acid & $202(38)$ & $171(95)$ \\
Glutamine & 116 & 164 \\
Proline & $32(6)$ & $62(54)$ \\
Glycine & $68(46)$ & $81(63)$ \\
Alanine & $215(13)$ & $206(48)$ \\
$\alpha$-Aminobutyric acid & 39 & 25 \\
Valine & $128(8)$ & $160(39)$ \\
Cystine & $10(4)$ & $8(5)$ \\
Methionine & 59 & $64(19)$ \\
Cystathionine & 12 & 8 \\
Isoleucine & $85(9)$ & $105(27)$ \\
Leucine & $180(16)$ & $240(45)$ \\
Tyrosine & $69(10)$ & $91(26)$ \\
Phenylalanine & $58(10)$ & $80(23)$ \\
$\beta$-Alanine & $99(6)$ & $64(5)$ \\
$\beta$-Aminoisobutyric acid & 8 & 6 \\
Ethanolamine & $64(141)$ & $58(103)$ \\
Tryptophan & 33 & 22 \\
Lysine & $123(17)$ & $128(50)$ \\
Histidine & $50(7)$ & $49(14)$ \\
Arginine & $62(14)$ & $149(36)$ \\
& & \\
Total & $3,112(439)$ & $3,062(804)$ \\
Nitrogen recovered (\%) & $68(13)$ & $65(19)$ \\
Ammonia & 30 & 56 \\
\hline * The amounts of combined amino acids are given in paren- \\
theses. & & \\
& &
\end{tabular}

of CAA increased during the salting, indicating that a considerable amount of oligopeptides was produced.

\section{Nucleotides and Related Compounds}

Various kinds of nucleotides and related compounds were detected in the raw material, but their levels were very low (Table 3 ); the constituents exceeding $20 \mathrm{mg}$ were only inosine and CMP. The Alaska pollack roe seemed to be a little more abundant in nucleotides and related compounds than the mullet roe. ${ }^{1)}$ Most of these constituents declined more or less during the salting.

\section{Other Nitrogenous Constituents}

A relatively high level of creatine $(85 \mathrm{mg})$ and a very low level of creatinine $(1 \mathrm{mg})$ were present in the raw material (Table 4). In "Tarako", the former decreased considerably, while the latter 
Table 3. Nucleotides and related compounds in raw and salted Alaska pollack roe ("Tarako")

\begin{tabular}{|c|c|c|}
\hline \multirow[b]{2}{*}{-} & \multicolumn{2}{|c|}{ (mg/100 $\mathrm{g}$ dry matter) } \\
\hline & $\begin{array}{c}\text { Raw } \\
\text { material }\end{array}$ & "Tarako" \\
\hline GDP & $+t$ & 1 \\
\hline ADP & 1 & ++ \\
\hline CDP & 1 & ++ \\
\hline GMP & 7 & 2 \\
\hline AMP & 3 & 1 \\
\hline IMP & 17 & 4 \\
\hline CMP & 33 & 4 \\
\hline UMP & + & 1 \\
\hline $\mathrm{NAD}^{+}$ & 19 & 3 \\
\hline Guanosine & 10 & 9 \\
\hline Adenosine & + & + \\
\hline Inosine & 43 & 40 \\
\hline Cytidine & 16 & 16 \\
\hline Uridine & 19 & 13 \\
\hline Guanine & + & + \\
\hline Adenine & + & ++ \\
\hline Hypoxanthine & 19 & 12 \\
\hline Cytosine & 2 & 3 \\
\hline Uracil & 14 & 7 \\
\hline
\end{tabular}

+ , trace; ++ , less than $0.4 \mathrm{mg} / 100 \mathrm{~g}$ dry matter.

Table 4. Other nitrogenous components in the extracts of raw and salted Alaska pollack roe ("Tarako")

\begin{tabular}{lcc} 
& \multicolumn{2}{c}{ (mg/100 g dry matter) } \\
\hline & $\begin{array}{c}\text { Raw } \\
\text { material }\end{array}$ & "Tarako" \\
\hline Creatine & 85 & 54 \\
Creatinine & 1 & 3 \\
Carnitine & 1 & + \\
Glycinebetaine & 2 & ++ \\
Homarine & 7 & 5 \\
Trigonelline & 37 & 28 \\
TMAO & 46 & 4 \\
TMA & 5 & 12 \\
\hline
\end{tabular}

+ , trace; ++ , less than $0.4 \mathrm{mg} / 100 \mathrm{~g}$ dry matter

changed little.

As for quaternary ammonium bases in the raw material, trimethylamine oxide (TMAO, $46 \mathrm{mg}$ ) and trigonelline $(37 \mathrm{mg}$ ) were the principal constituents, and homarine $(7 \mathrm{mg})$, glycinebetaine $(2 \mathrm{mg})$, and carinitine $(1 \mathrm{mg})$ were the minor ones (Table 4). All of these compounds decreased during the salting, but the decreasing rate of TMAO was very high. The diminution of TMAO was accompanied by a rise of trimethylamine (TMA) from $5 \mathrm{mg}$ to $12 \mathrm{mg}$.

\section{Sugars and Organic Acids}

Nine sugars were identified in both samples as
Table 5. Nonnitrogenous components in the extracts of raw and salted Alaska pollack roe ("Tarako")

(mg/100 $\mathrm{g}$ dry matter)

\begin{tabular}{lrr}
\hline & $\begin{array}{c}\text { Raw } \\
\text { Material }\end{array}$ & "Tarako" \\
\hline Sugars: & & \\
Glyceraldehyde & 25 & 76 \\
Glucose & 10 & 26 \\
D-Mannitol & 37 & 51 \\
Dulcitol & 3 & 6 \\
myo-Inositol & 79 & 39 \\
Sucrose & 13 & 13 \\
Maltose & 1 & 1 \\
Mannose & 20 & 29 \\
Glucuronic acid & 3 & 1 \\
Organic acids: & & \\
Lactic acid & 241 & 225 \\
Succinic acid & 13 & 1 \\
Acetic acid $_{\text {Inorganic ions: }}$ & 49 & 16 \\
PO $^{3-}$ & & \\
$\mathrm{Cl}^{-}$ & 491 & 107 \\
$\mathrm{Na}^{+}$ & 1,095 & 8,817 \\
$\mathrm{~K}^{+}$ & 399 & 5,135 \\
$\mathrm{Ca}^{2+}$ & 367 & 354 \\
$\mathrm{Mg}^{2+}$ & 1 & 1 \\
& 1 & 5 \\
\hline & & \\
\hline & 13 & \\
& &
\end{tabular}

shown in Table 5. Among them, myo-inositol, D-mannitol, glyceraldehyde, and mannose (20-79 mg) were the major sugar constituents in the raw material. Sucrose, glucose, dulcitol, glucuronic acid, and maltose were also present in small amounts. It is noteworthy that the Alaska pollack roe was rich in sugar alcohols. Most of the sugars increased during the salting, but myo-inositol, the most abundant sugar component, was reduced by half.

With respect to organic acids, a large amount of lactic acid $(241 \mathrm{mg}$ ) was found in the raw material with smaller amounts of acetic (49 mg) and succinic $(13 \mathrm{mg})$ acids. During the processing into "Tarako", lactic acid declined little, but the other two acids dropped sharply.

\section{Inorganic Ions}

As demonstrated in Table $5, \mathrm{Cl}^{-}, \mathrm{PO}_{4}{ }^{3-}, \mathrm{Na}^{+}$, and $\mathrm{K}^{+}$were detected as the major inorganic ions in the raw material. In "Tarako", the contents of $\mathrm{Cl}^{-}$and $\mathrm{Na}^{+}$were increased substantially due to the brine treatment. On the other hand, the level of $\mathrm{PO}_{4}{ }^{3-}$ was lowered to less than one fourth, and $\mathrm{K}^{+}$was kept at the almost same level.

Distribution of Various Components in the Extracts

The nitrogen distribution in the extracts is 


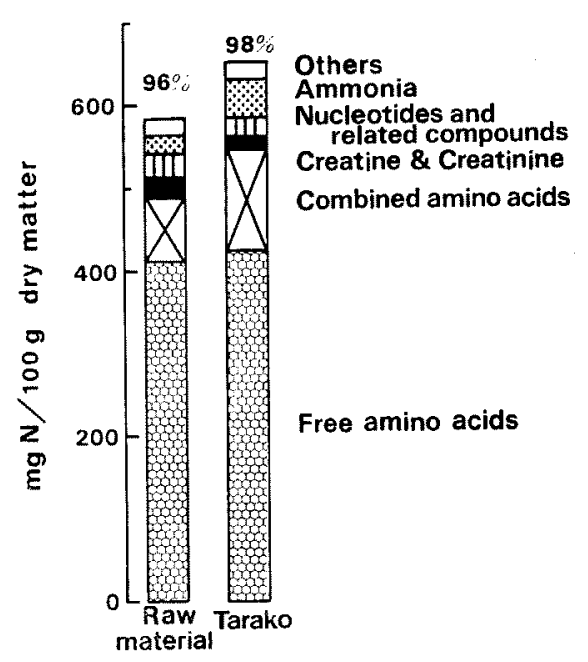

Fig. 1. Nitrogen distribution in the extracts of raw and salted Alaska pollack roe ("Tarako"). The figures at the top of the columns indicate the recovery on nitrogen basis.

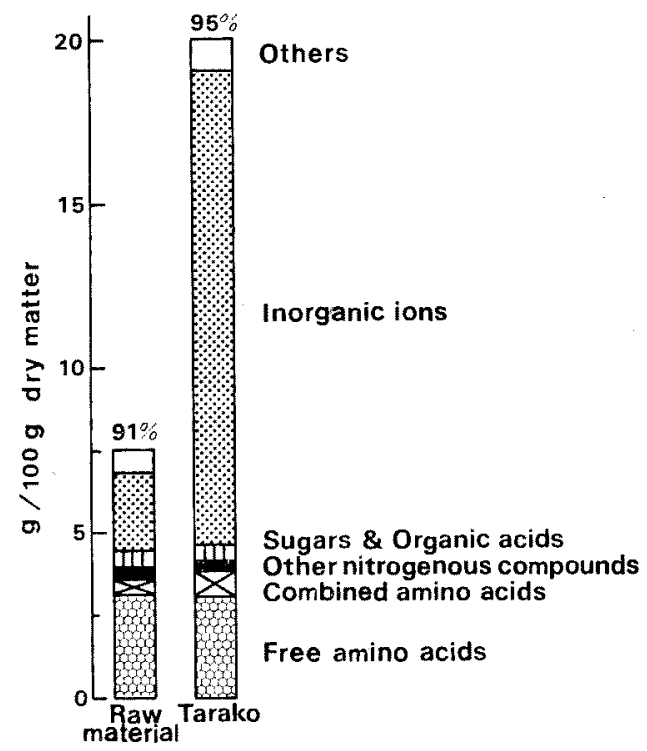

Fig. 2. Distribution of various components in the extracts of raw and salted Alaska pollack roe ("Tarako"). The figures at the top of the columns indicate the recovery on weight basis.

presented in Fig. 1, which clearly shows that FAA are the most prominent nitrogenous components, occupying $68 \%$ and $65 \%$ of $\mathrm{EN}$ in the raw material and "Tarako", respectively. The recoveries of EN were very high, being more than $95 \%$ in both extracts.

Fig. 2 shows the distribution of the analyzed components in the extracts. The recoveries of dry matter of the extracts were $91 \%$ for the former and $95 \%$ for the latter. It is apparent from the figure that the extractives of "Tarako" consisted mostly of minerals and FAA, suggesting that those components are most influential to its flavor.

\section{Discussion}

"Tarako" is produced from Alaska pollack roe by a simple procedure, i.e., brine-salting. Since "Tarako" is reputed to be much more palatable than the raw material, it has been anticipated that considerable changes in taste-active components must occur during the simple processing. However, the changes in FAA that have been proved to be important flavor components in some seafoods, ${ }^{5-7)}$ were not so remarkable, differing from the mullet roe whose FAA increased considerably during the processing." ${ }^{1)}$ Furthermore, the umami-giving nucleotides such as GMP, IMP, and AMP were decreased. The taste-active components that increased significantly during the processing were only two inorganic ions, $\mathrm{Na}^{+}$and $\mathrm{Cl}^{-}$. But it should be pointed out that the amount of FAA in the raw material of "Tarako" (Alaska pollack roe) was considerably higher than that in the raw material of "Karasumi" (mullet roe) and was even superior to that in "Karasumi". Thus it may be reasonable to assume that the large amount of increased FAA contributes to the flavor in the case of "Karasumi", whereas the large amount of inherent FAA does in the case of "Tarako".

The importance of $\mathrm{Na}^{+}$and $\mathrm{Cl}^{-}$in producing the flavor of seafoods has been recognized. ${ }^{3-7)}$ They should participate not only in salty taste of "Tarako" but also in its characteristic flavor jointly with FAA.

\section{Acknowledgment}

The authors are grateful to Nippon Suisan Kaisha, Ltd. for generous supply of the samples.

\section{References}

1) T.-K. Chiou and S. Konosu: Nippon Suisan Gakkaishi, 54, 307-313 (1988).

2) Statistics and Information Dept., Ministry of Agriculture, Forestry and Fisheries of Japan: Suisanbutsu Ryutsu Tokei Nenpo, Tokyo (1987).

3) T. Suzuki and M. Suyama: Nippon Suisan Gakkaishi, 49, 1747-1753 (1983).

4) K. Watanabe, T. Shimizu, and S. Konosu: 
Nippon Suisan Gakkaishi, 40, 731 (1974).

5) S. Konosu: in "Food Taste Chemistry" (ed. by J. C. Boudreau), Amer. Chem. Soc., Washington D. C., 1979, pp. 186-203.

6) "S. Konosu, T. Hayashi, and K. Yamaguchi: in "Umami: A Basic Taste" (ed. by K. Kawamura and M. R. Kare), Marcel Dekker, Inc., New
York and Basel, 1987, pp. 235-269.

7) S. Konosu, K. Watanabe, and K. Yamaguchi: in "Food Acceptance and Nutrition" (ed. by J. Solms, D. A. Booth, R. M. Pangborn, and O. Raunhardt), Academic Press, London, 1987, pp. 143-155. 